\title{
RESEARCH
}

Open Access

\section{Wealth-based equity in maternal, neonatal, and child health services utilization: $a$ cross-sectional study from Ethiopia}

\author{
Alem Desta Wuneh ${ }^{1 *}$ (D, Araya Abrha Medhanyie ${ }^{1}$, Afework Mulugeta Bezabih ${ }^{1}$, Lars Åke Persson ${ }^{2,3}$, \\ Joanna Schellenberg ${ }^{2}$ and Yemisrach Behailu Okwaraji ${ }^{2,3}$
}

\begin{abstract}
Background: Despite the pro-poor health policies in Ethiopia, the utilization of maternal, neonatal, and child health services remains a challenge for the country. Health equity became central in the post-2015 Sustainable Development Goals globally and is a priority for Ethiopia. The aim of this study was to assess equity in utilization of a range of maternal and child health services by applying absolute and relative equity indices.

Methods: Data on maternal and child health utilization emanated from a baseline survey conducted for a large project 'Optimizing the Health Extension Program from December 2016 to February 2017 in four regions of Ethiopia. The utilization of four or more antenatal care visits; skilled birth attendance; postnatal care within 2 days after childbirth; immunization with BCG, polio 3, pentavalent 3, measles and full immunization of children aged 1223 months; and vitamin A supplementation for 6-23 months old children were stratified by wealth quintiles. The socioeconomic status of the household was assessed by household assets and measured by constructing a wealth index using principal component analysis. Equity was assessed by applying two absolute inequity indices (Wealth index [quintile 5- quintile 1] and slope index of inequality) and two relative inequity indices (Wealth index [quintile5: quintile1] and concentration index).

Results: The maternal health services utilization was low and inequitably distributed favoring the better-off women. About 44, 71, and 18\% of women from the better-off households had four or more antenatal visits, utilized skilled birth attendance and postnatal care within two days compared to 20,29, and $8 \%$ of women from the poorest households, respectively. Skilled birth attendance was the most inequitably distributed maternal health service. All basic immunizations: BCG, polio 3, pentavalent 3, measles, and full immunization in children aged 12-23 months and vitamin A supplementation were equitably distributed.

Conclusion: Utilization of maternal health services was low, inequitable, and skewed against women from the poorest households. In contrast, preventive child health services were equitably distributed. Efforts to increase utilization and reinforcement of pro-poor and pro-rural strategies for maternal, newborn and immunization services in Ethiopia should be strengthened.
\end{abstract}

Keywords: Wealth-based equity, Maternal health services utilization, Child health services utilization, Wealth quintile, Concentration index, Slope index of inequity, Ethiopia

\footnotetext{
* Correspondence: alemdw@gmail.com

'School of Public Health, College of Health Sciences, Mekelle University,

Mekelle, Ethiopia

Full list of author information is available at the end of the article
}

C The Author(s). 2019 Open Access This article is distributed under the terms of the Creative Commons Attribution 4.0 International License (http://creativecommons.org/licenses/by/4.0/), which permits unrestricted use, distribution, and

reproduction in any medium, provided you give appropriate credit to the original author(s) and the source, provide a link to the Creative Commons license, and indicate if changes were made. The Creative Commons Public Domain Dedication waiver (http://creativecommons.org/publicdomain/zero/1.0/) applies to the data made available in this article, unless otherwise stated. 


\section{Background}

Health and health care services are inequitably distributed between and within countries [1]. Wealth-based inequities in the utilization of maternal, neonatal and child health $(\mathrm{MNCH})$ services exist in low-income countries [2]. An analysis in Sub-Saharan Africa (SSA) showed that countries with an improved equitable utilization in maternal and child health services had demonstrated a continued reduction in maternal and child mortality, though inequities in utilization still persisted [3]. These patterns in the utilization of maternal, neonatal, and child health services are also found in the Ethiopian context [4].

In this study, equity is defined based on the concept of equal utilization of services for equal needs $[1,5]$. Evidences show that women and children in disadvantaged population subgroups have lower coverage of preventive services and utilization of health care and worse health outcomes than the more advantaged [6, 7]. As a result, the poor suffer higher rates of morbidity and mortality than the better-off and often use health services less despite higher needs [8]. These inequities are serious public health concerns with social and economic implications [6-8]. Thus, health equity became central in the post-2015 Sustainable Development Goals (SDGs) globally [9] and it is also a priority for Ethiopia [10].

Ethiopia has implemented pro-poor health policy through a number of health programs that have demonstrated considerable improvements in maternal and child health services, such as health extension program, health development army, scale-up of community-based health insurance schemes $[4,11]$. Existing evidence has, however, shown high levels of inequity in the $\mathrm{MNCH}$ services utilization favoring the better-off population subgroups $[12,13]$. Nevertheless, few studies have found an equitable distribution in the coverage of immunization across all socioeconomic groups [14].

However, previous studies have demonstrated mixed findings regarding equity in the utilization of $\mathrm{MNCH}$ services in Ethiopia [4, 12, 15], also varying by equity measurement used and indices of equity analysis applied. In most of these studies, equity was assessed by applying a single index $[4,16]$. This study has used a combination of indices to provide a comprehensive picture of equity in the utilization of services, which is highly recommended [17]. There has been a dynamic and rapid development in socio-economic conditions in Ethiopia in the last couple of decades that may have influenced the utilization of maternal, neonatal, and child health services $[18,19]$. Such transitions may also influence the distribution of health services utilization. Thus, the aim of this study was to assess equity in the utilization of a range of maternal and child health services by applying absolute and relative equity indices.

\section{Methods}

\section{Study setting and design}

The study was conducted in ten zones of four regions in Ethiopia, namely Amhara, Oromia, Southern Nations, Nationalities and Peoples (SNNP), and Tigray. These regions cover more than $85 \%$ of the total population of the country. Agriculture is the predominant source of economy in these regions. Ethiopia has one of the lowest income per capita but is one of the fastest-growing economies in Africa with an increment in Gross Domestic Product of 7\% since 2014 [19]. The health care system is three-tiered: primary, secondary, and tertiary-level of care.

\section{Data source}

The present study was part of an evaluation of the large project entitled "Optimizing the Health Extension Program" (OHEP) that aimed at improving services utilization of the integrated community case management of childhood illnesses (ICCM) and the community-based newborn care $(\mathrm{CBNC})$. The beneficiaries of the intervention are the caretakers and their children under five years, who are the study subjects of this survey. The evaluation of the intervention has been registered in the trial registration Current Controlled Trials ISRCTN12040912. The data were collected from December 2016 to February 2017. A two-stage stratified cluster sampling technique was used to select the study subjects. First, 200 Enumeration Areas (EAs) were selected in the study areas. Each enumeration area formed one cluster that was the primary sampling unit. Second, all households, as secondary sampling units, within a cluster were listed as a sampling frame. Of the listed households, 30 were selected using systematic random sampling. Overall, a total of 6000 households were sampled but data were collected from 5714 households. Data from six EAs in the SNNP region were not collected for security reasons.

\section{Measurements}

Nine indicators were used to assess equity in the utilization of $\mathrm{MNCH}$ services. The first three were maternal indicators: four or more antenatal care visits (ANC4+), skilled birth attendance (SBA), and postnatal care visits within two days (PNC). These maternal indicators were based on interviews with women who had a live birth in the past 12 months before the survey. Skilled birth attendance was defined as a dichotomous variable where mothers were coded as having delivered by a skilled birth attendant if they received delivery care by skilled health attendant [20]. Child immunization indicators included BCG, three polio immunizations, three pentavalent immunizations, measles and full immunization of children 12-23 months of age. Information on vitamin A supplementation included children aged 6-23 months [7, 12]. Utilization for all immunization types was based on the 
combined information recorded on the child's vaccination card with responses from the caretaker in case of missing immunization card information. Full immunization coverage was defined as the percentage of children aged 12-23 months, who had received one dose of BCG vaccine, three doses of the polio vaccine, three doses of pentavalent vaccine, and one dose of measles vaccine [21]. Utilization of vitamin A supplementation was defined as children aged 6-23 months who had received vitamin A supplementation in the six months preceding the survey. These variables were coded as 1 when the respondent or child had received the service and 0 when the respondent had not received the service.

\section{Construction of socioeconomic status}

The socioeconomic status of each household was constructed using principal component analysis (PCA) of household assets followed by stratification of the households into wealth quintiles [22]. The analysis was done by aggregating the ownership of durable assets; access to utilities and infrastructure; and housing characteristics; ownership of a house and ownership of livestock variables into a single proxy variable of household wealth. All asset variables were coded into binary variables. Asset variables with zero standard deviations were excluded from the PCA as they did not contribute to the analysis. The first component of the PCA was used to construct the wealth quintiles [22]. Based on the PCA weights for each asset variable, an aggregated score was calculated for each of the surveyed households, which was grouped into quintiles with quintile 1 (Q1) representing the poorest $20 \%$ of households in the sample and quintile 5 (Q5) representing 20\% of the better-off. The study subjects were thereafter grouped into quintiles based on their household wealth scores.

\section{Equity analyses}

Two absolute and two relative equity measures were used to assess equity in the utilization of maternal, neonatal and child health services based on household wealth quintiles. For a given health indicator, the absolute inequity reflects the magnitude of absolute difference in health services utilization between the two subgroups (Q5-Q1) and the slope index of inequity (SII) across the entire distribution of socioeconomic status. The relative inequity measures the ratio (Q5: Q1) and the concentration index (CIX) in health services utilization. The CIX and SII, including standard errors [12] and $p$-values, were assessed using commands downloaded from the International Center for Equity in Health $[17,23]$. The utilization of the services by the wealth quintiles and the distance between the wealth quintiles were graphically depicted using equiplot [12, 24]. STATA 14.1 (StataCorp, Texas, USA) was used to analyze the data. During the analysis, all the commands were preceded with svy to account for the clustering.

\section{Results}

Participation of study subjects

Data were collected from 5714 rural households. A total of 6321 women aged 13 to 49 years old participated in the study with a response rate of $95 \%$. Most of the women (57\%) were Christian Orthodox followers and about $46 \%$ of them had not attended formal education. Thirty-seven percent of the women were in the age group of fewer than 20 years and $38 \%$ were in the age group of 20-34 years. Of the 6321 women, 714 had a live birth in the last 12 months prior to the survey. There were 3110 children under the age of five years of whom $567(18 \%)$ were in the age interval of $12-23$ months, while $51 \%$ were girls.

\section{Ownership of assets}

Table 1 describes the ownership of the durable assets, utilities and housing characteristics by wealth quintiles. As expected, the ownership of durable assets increased by wealth quintiles, i.e., the better-off households were more likely to own durable assets than the poorest. In addition, the houses from the better-off quintiles were characterized by having an improved water source and an improved latrine. The poorest quintiles were less likely to have an iron roof, but more likely to own the

Table 1 Percent of households $(n=5714)$ with specific durable assets and utilities by wealth quintile

\begin{tabular}{lllllll}
\hline Assets and utilities & Q1 & Q2 & Q3 & Q4 & Q5 & Overall \\
\hline Ownership of durable assets & & & & & & \\
Wristwatch & 16 & 18 & 21 & 26 & 27 & 22 \\
Gold & 0 & 2 & 3 & 8 & 25 & 8 \\
Mobile phone & 20 & 42 & 58 & 77 & 89 & 57 \\
Radio & 15 & 20 & 30 & 44 & 47 & 31 \\
Bed & 13 & 41 & 66 & 76 & 84 & 56
\end{tabular}

Housing characteristics and utilities

$\begin{array}{lllllll}\text { Electricity } & 0 & 0 & 2 & 13 & 73 & 18 \\ \text { Kerosene lamp } & 17 & 14 & 14 & 12 & 9 & 13 \\ \text { Solar energy } & 52 & 47 & 41 & 38 & 27 & 41 \\ \text { Electricity for cooking } & 0 & 0 & 0 & 0 & 17 & 3 \\ \text { Iron roof } & 26 & 54 & 75 & 88 & 97 & 68 \\ \text { Improved toilet facility } & 43 & 72 & 81 & 89 & 94 & 76 \\ \text { Improved source of water } & 30 & 54 & 73 & 86 & 95 & 68\end{array}$

Ownership of house, land, and livestock

\begin{tabular}{lllllll} 
Own house & 100 & 100 & 99 & 94 & 65 & 92 \\
Own agriculture land & 96 & 91 & 87 & 77 & 40 & 78 \\
Own livestock & 81 & 72 & 69 & 54 & 25 & 60 \\
\hline
\end{tabular}


houses where they lived, and more likely to own agricultural land, compared to the better-off.

\section{Maternal health services utilization}

Thirty percent of the women had four or more antenatal care visits, $48 \%$ had a skilled attendant at their most recent childbirth and just $12 \%$ had a postnatal care visit within two days after birth (Table 2 and Fig. 2).

There were differences in the utilization of maternal health services between the better-off and poorest population subgroups. The utilization of ANC4+ visits, SBA, and PNC were 20,29 , and $8 \%$, in the poorest wealth quintile and 44,71 , and $18 \%$, respectively, in the betteroff wealth quintile. This resulted in a wide absolute inequity gap (Q5-Q1) between the better-off and poorest wealth quintiles for SBA (42 percentage points) and moderate for ANC4+ visits (24 percentage points). Postnatal care had a more limited inequity gap (10 percentage points) (Table 2 and Fig. 2). These findings imply that there were wide differences in the utilization of these three services across the wealth quintiles favoring the better-off. Also, the values of the SII for ANC4+ visits (22 percentage points), SBA (46 percentage points) and PNC (9 percentage points) (Table 2) indicate that the utilization of maternal services was concentrated to the better-off wealth quintiles.

The analysis of relative difference (Q5: Q1) showed that women from the better-off group were 2.2, 2.5 and 2.2 times more likely to have utilized ANC4+ visits, SBA and PNC services, respectively, compared to the poorest wealth quintile (Table 2). Correspondingly, the positive value of CIX for ANC4+, SBA, and PNC were 13.2, 17.5, and $14.1 \%$, respectively, which indicated that there was inequity in the utilization of the services with the betteroff mothers utilizing the services more than the poorest (Table 2 and Fig. 1).

\section{Child health services utilization}

Table 2 and Fig. 2 present the overall distribution in utilization of the six selected child health services and the inequity indices for these services. Close to two-thirds of children aged 12-23 months had received polio 3 and BCG immunizations, 54\% of the children had received pentavalent 3 , and $61 \%$ had measles immunization. Only $41 \%$ had been fully vaccinated.

The absolute inequity for all four basic immunizations showed slight differences in the utilization with a value of -4 percentage points for BCG immunization, -3 percentage points for polio $3,-1$ percentage points for pentavalent $3,-3$ percentage points for measles, and -5 percentage points for full immunization. This implies that utilization of the four basic immunization types was in favor of the poorest wealth quintiles but with very small differences. Similarly, the slope index of inequity was negative for all the vaccination types, indicating that the utilization was slightly higher among individuals in the poorest wealth quintiles. But, the relative inequity

Table 2 Wealth-based inequities in utilization of selected maternal and child health services

\begin{tabular}{|c|c|c|c|c|c|c|c|c|c|c|c|c|}
\hline \multirow[t]{2}{*}{$\begin{array}{l}\text { Type of child } \\
\text { health services }\end{array}$} & \multirow{2}{*}{$\begin{array}{l}\text { No of } \\
\text { subjects } \\
\text { n }\end{array}$} & \multirow{2}{*}{$\begin{array}{l}\text { Overall } \\
\text { utilization } \\
\%\end{array}$} & \multirow{2}{*}{$\begin{array}{l}\text { Q1 } \\
\text { utilization } \\
\%\end{array}$} & \multirow{2}{*}{$\begin{array}{l}\text { Q5 } \\
\text { utilization } \\
\%\end{array}$} & \multirow{2}{*}{$\begin{array}{l}\text { Difference } \\
\text { (Q5-Q1; \% points) } \\
\%\end{array}$} & \multicolumn{3}{|c|}{$\begin{array}{l}\text { Slope index of } \\
\text { inequity /SII } \\
\text { ( } \% \text { points) }\end{array}$} & \multirow{2}{*}{$\begin{array}{l}\text { Ratio (Q5: Q1) } \\
\text { value }\end{array}$} & \multicolumn{3}{|c|}{$\begin{array}{l}\text { Concentration } \\
\text { index/CIX (X100) }\end{array}$} \\
\hline & & & & & & $\%$ & SE & $P$ & & $\%$ & SE & $P$ \\
\hline \multicolumn{13}{|l|}{ Maternal health services } \\
\hline $\begin{array}{l}\text { Antenatal care } \\
\text { (4 or more visits) }\end{array}$ & 714 & 30 & 20 & 44 & 24 & 22.0 & 5.8 & $<0.001$ & 2.2 & 13.2 & 3.3 & $<0.001$ \\
\hline Skilled birth attendance & 714 & 48 & 29 & 71 & 42 & 46.0 & 5.4 & $<0.001$ & 2.5 & 17.5 & 2.1 & $<0.001$ \\
\hline $\begin{array}{l}\text { Postnatal care } \\
\text { (within two days) }\end{array}$ & 714 & 12 & 8 & 18 & 10 & 9.0 & 4.2 & 0.042 & 2.2 & 14.1 & 6.0 & 0.020 \\
\hline \multicolumn{13}{|l|}{ Child health services } \\
\hline BCG immunization & 567 & 66 & 69 & 65 & -4 & -9.5 & 6.8 & 0.163 & 0.94 & -2.4 & 1.7 & 0.170 \\
\hline Polio 3 immunization & 567 & 64 & 66 & 63 & -3 & -6.1 & 6.9 & 0.380 & 0.95 & -1.8 & 1.8 & 0.338 \\
\hline $\begin{array}{l}\text { Pentavalent } 3 \\
\text { immunization }\end{array}$ & 567 & 54 & 56 & 57 & -1 & -1.7 & 7.2 & 0.810 & 1.02 & -0.3 & 2.2 & 0.911 \\
\hline Measles immunization & 567 & 61 & 60 & 57 & -3 & -7.0 & 7.2 & 0.326 & 0.95 & -2.1 & 1.9 & 0.286 \\
\hline Full immunization & 567 & 41 & 42 & 44 & -2 & -5.0 & 7.2 & 0.488 & 1.05 & -1.8 & 3.0 & 0.548 \\
\hline $\begin{array}{l}\text { Vitamin A } \\
\text { supplementation }\end{array}$ & 924 & 57 & 60 & 57 & -3 & -5.1 & 5.6 & 0.361 & 0.95 & -0.7 & 1.6 & 0.662 \\
\hline
\end{tabular}

Immunization coverage was computed for children aged 12-23 months and vitamin A supplementation for 6-23 months old. CIX- concentration index, SII-slope index of inequity. SE-standard error, Q1-wealth quintile 1 (20\% poorest), Q5-wealth quintile 5 ( $20 \%$ better-off), 95\%Cl- 95\% confidence interval. "Difference" (Q5$\mathrm{Q} 1)$ is a measure of an absolute difference in utilization of the services between the better-off (Q5) and poorest (Q1); "Ratio" is a measure of relative inequity of Q5 divided by Q1. The SII is an estimate of absolute inequity that takes the whole population into account and interpreted as the percentage point difference. The CIX is an estimate of relative inequity which takes the whole population into account. For all equity indices, the results are presented in percentages. 

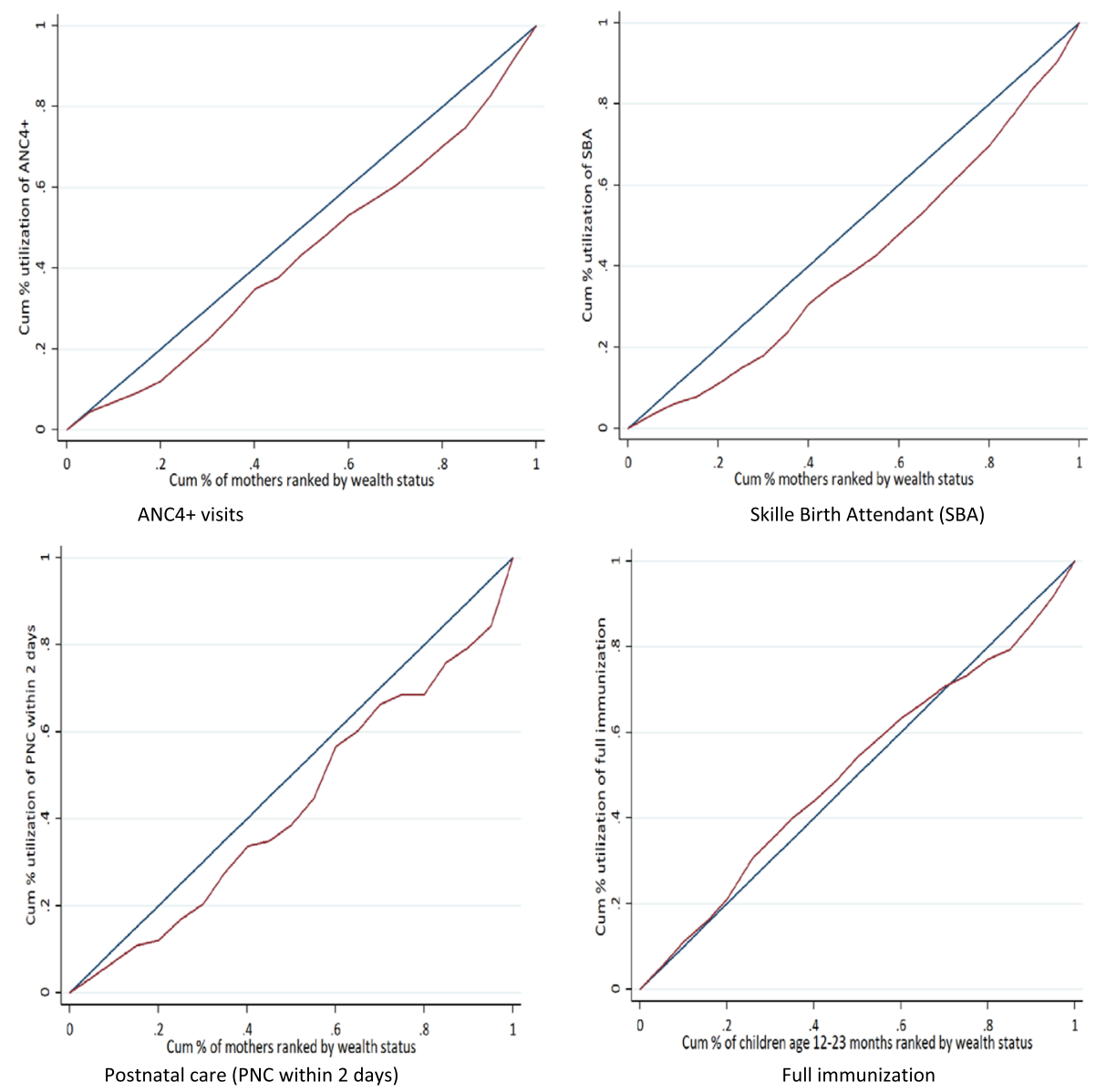

Fig. 1 Concentration curve for selected maternal and child health services by wealth quintiles

(Q5: Q1) did not show any inequity in the utilization of these immunizations across the better-off and poorest children as the values for all are one or close to one (Table 2).

The concentration index for all the basic immunizations: BCG $(-2.4 \%)$, Polio $3(-1.8 \%)$, Pentavalent 3 $(-0.3 \%)$, and measles $(-2.1 \%)$ did not show any statistically significant differences in the utilization of all the four basic immunizations (Table 2). Also, the negative values of the slope index of inequity $(-5.0$ percentage points) and concentration index $(-1.8 \%)$ in the utilization of full immunization were small (Table 2).

The absolute inequity results for vitamin A supplementation in children 6-23 months of age indicated that there was a small gap of -3 percentage points, with a utilization rate of $60 \%$ in the poorest and $57 \%$ in the better-off. The concentration index $(-0.7 \%)$ and slope index of inequity ( -5.1 percentage points) indicated that the utilization of this service was concentrated among children in the poor wealth quintiles (Table 2).
Figure 2 illustrates the percent utilization and distribution of the maternal and child health services by wealth quintiles. ANC4+ visits, SBA and PNC (within two days) displayed a wide gap in utilization by wealth quintiles. This implies that maternal health services utilization was higher in the better-off. No immunizations showed differences in utilization by wealth quintiles. The distance between dots for all immunization types and vitamin A supplementation was close, indicating that the utilization of these services was more-or-less equitable.

\section{Discussion}

This study showed mixed results regarding equity in the utilization of the selected maternal and child health services. The maternal health services utilization was inequitably distributed across the socioeconomic groups, with the better-off mothers being more likely to use these services. Having a skilled attendant at birth was the most inequitably distributed service, whilst four or more antenatal care visits and post-natal care within two days were 


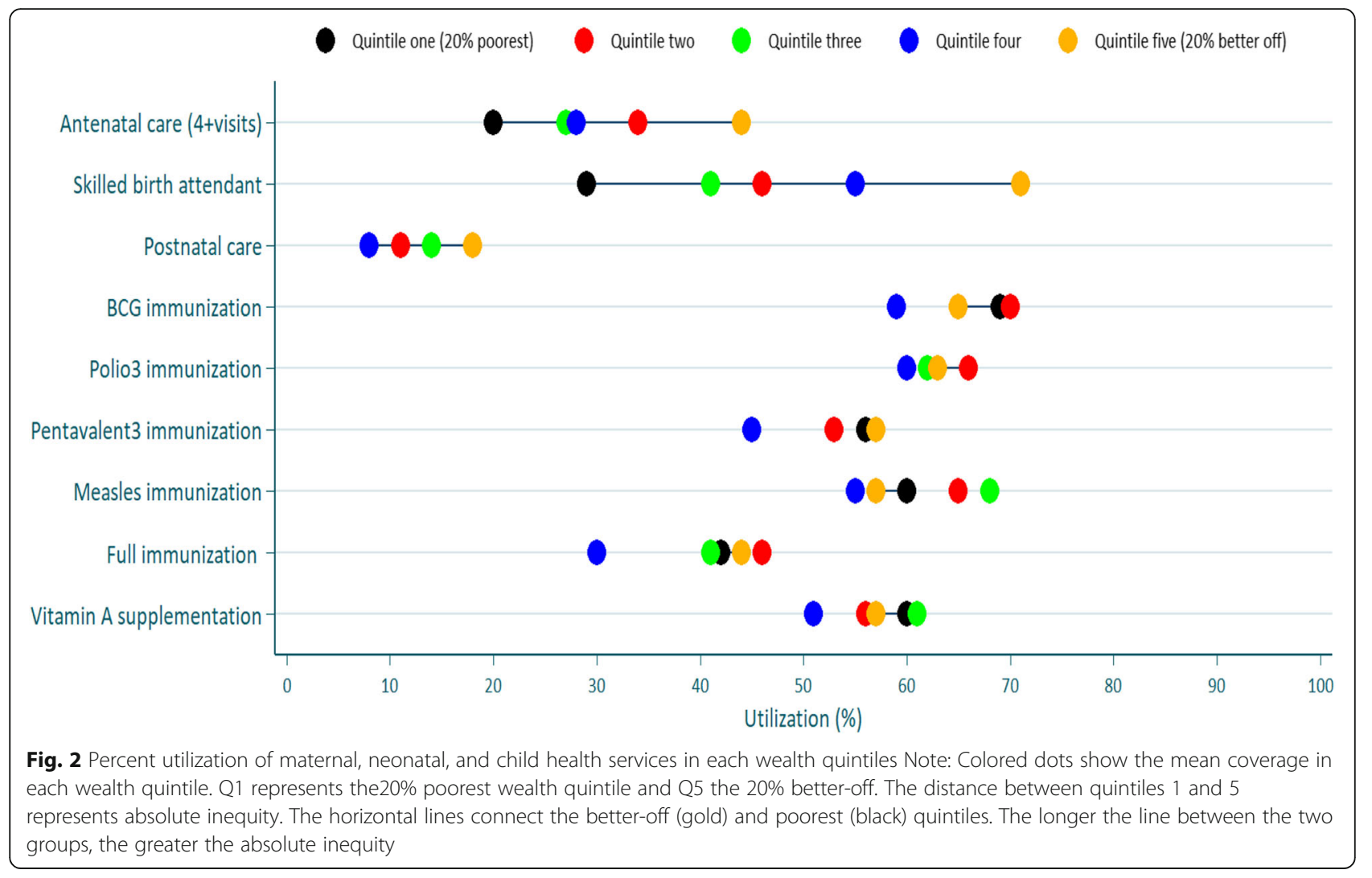

moderately inequitable. In contrast, the utilization of all the basic childhood immunizations for children aged 1223 months and vitamin A supplementation tended to be equitably distributed between the poorest and better-off.

The overall level of utilization of maternal health services remained low, which is consistent with the recent Ethiopian Demographic and Health Survey 2016 results [13]. Also, the coverage of immunizations and vitamin A supplementation was suboptimal, though, with a slightly higher levels than the national-level EDHS 2016 report [13].

In this study, maternal health services utilization tended to be inequitably distributed favoring mothers from the better-off socioeconomic group. Level of services utilization and equity in services utilization are interrelated, in that a low level of utilization is associated with high inequity in the use of services [12, 17, 25].

Inequities in maternal health services utilization were documented in the recent Ethiopian Demographic and Health Survey 2016 results [13] and found also in other recent studies in Ethiopia [16, 18, 26]. This finding is also consistent with the multi-country and multi-year analysis from sub-Saharan African countries [3], which has reported inequity in the utilization of antenatal care visits and facility-based delivery favoring mothers from the better-off socioeconomic status. Similar results have also been reported from other sub-Sharan African countries, such as Benin [27], Burkina Faso [28], and Nigeria [29], and other low- and middle-income countries, such as Philippines [30], Afghanistan [31], and Bangladesh [32]. In contrast, studies in Pakistan [33] and Myanmar [34] found equitable distribution in the utilization of four or more antenatal care visits.

This study was conducted in a rural part of the country, where a majority of the households have a low economic status and the health care infrastructure is weak with limited access to maternal health services [18], which is a constraint especially for poor people to use these services. Maternal health services utilization could be attributed to direct medical and non-medical costs for accessing the services, transport costs $[18,25,35]$ and opportunity costs of the services [36] which cannot be afforded by the poorest women despite the fact that maternal health services are provided free to all mothers in Ethiopia [18, 27]. Women from higher socioeconomic groups may be empowered, have more autonomy and access to more economic resources than their poorer counterparts to use these services [36]. The health extension workers are responsible for linking mothers to health centers and hospitals but do not provide these maternal health services directly [37-39].

The utilization of all the studied childhood immunizations for children aged 12-23 months tended to be 
equitably distributed between the poorest and better-off. This is in line with findings from other studies in Ethiopia [4] and Pakistan [33]. In contrast, the Ethiopian Demographic and Health Survey 2016 [13], as well as reports from other low-and middle-income countries $[21,36]$, have shown immunization coverage in favor of the better-off. This difference in findings can partly be explained by the difference in samples.

This study was conducted in rural areas with a majority of the population being economically poor, having lower education levels, and where access to facilitybased services was limited. The EDHS [13] was based on a nationally representative sample that included urban settings (e.g., Addis Ababa) with a high immunization coverage (89\%) and rural and pastoralist areas (e.g., Afar) with least coverage (15\%). This can explain the differences in findings of equity in full immunization between our results and the EDHS 2016.

In the rural parts of Ethiopia, the routine child immunization services are provided through outreach services by the health extension workers and occasionally via national immunization campaigns [26]. The outreach services for vaccination are carried out once a month, at religious holidays and sometimes through campaigns targeting the rural poor. The health extension workers were given this task based on the principles of primary health care [4] to provide community-based services (e.g., immunization services) to improve equitable access to all population groups [16]. This service provision is also supported by the women's development groups, who are volunteer community health workers engaged in mobilizing mothers for immunization and other maternal and child health activities [38, 40]. Evidence shows that health extension workers are more effective in the provision of immunization services than maternal health services [39].

In this study, vitamin A supplementation tended to be equitably distributed among all children aged 12-23, which is expected as this supplementation is provided through campaigns to all children irrespective of their socioeconomic status. Though, this finding differs from the Ethiopian Demographic and Health Survey 2016 results.

In general, services delivered at fixed-level facilities, that are at health centers and hospitals, are more likely to be utilized by the better-off mothers [12, 31, 35] compared to the poorest mothers. This is the case for maternal health services in the Ethiopian healthcare delivery system [18], which is organized into three-tiered; the primary, secondary, and tertiary-level of care [10]. Services such as immunization and vitamin A supplementation that is close to the community and delivered through outreach services and campaigns by trained health extension workers, which are supported by women's development groups are more likely to be equitably distributed $[12,35]$.
The inequity shown in the utilization of maternal health services implies that ensuring equitable and universal coverage of maternal health services is a challenge for Ethiopia. And attaining the maternal, neonatal, and child health targets in the SDGs would be unlikely. Moreover, to improve overall coverage of high-quality services, interventions that target the poorest [4] may be needed. This may include efforts to reduce financial barriers for poor mothers [25, 41].

This study has strengths and limitations. The findings from this study are relevant for the study areas in the four regions in the country that represent the selected intervention and comparison areas. Although not being sampled to represent the four regions, the level of utilization of maternal and child health services was similar to those found by the Ethiopian Demographic and Health Survey 2016 [13] and other recent studies [16, 18, 42]. The retrospective reporting of services utilization during pregnancy and newborns periods would possibly be affected by recall bias. The studied maternal services were, however, in their recent pregnancy i.e., by analyzing data restricted to births occurring in the 12 months prior to the survey. The results on child immunizations, which were based on interviews with caregivers, would also potentially suffer from reporting bias. The information relies on caregivers' ability to accurately recall and report immunization, sometimes but not always supported by information in the immunization card. But the information on immunization used the same methodology as in the Demographic and Health Surveys. The equity assessment in this study included a range of selected maternal and child health services and was not limited to a single service indicator. We used a household wealth index to represent the social conditions of the families, while other characteristics, such as education level, urban or rural residency, could have revealed other nuances of equity in health service utilization.

\section{Conclusions}

Utilization of four or more antenatal care visits, skilled birth attendance, and postnatal care within two days was low and inequitably distributed. In contrast, the utilization of immunizations and vitamin A supplementation was equitably distributed but with an overall low coverage. Although increasing the overall coverage of services may also increase equity in utilization, the propoor and pro-rural strategies of Ethiopia need to be reinforced in order to overcome the social gaps in the use of maternal, neonatal and child health services and eventually contribute to the achievement of SDGs. Monitoring the progress of SDGs over time and evaluating the health system investment using a combination of equity indices is critical for the country. 


\section{Abbreviations}

ANC4 + : Antenatal care visits 4 or more; BCG: Bacilli Calmette-Guérin; CBNC: Community Based Newborn Care; CIX: concentration index in its relative form; EDHS: Ethiopian Demography and Health Survey; HEP: Health extension program; HEW: Health extension workers; iCCM: Integrated Community Case Management of Childhood Illnesses; MICS: Multi-Indicator Cluster Survey; MNCH: Maternal, Neonatal, and Child Health; OHEP: Optimizing Health Extension Program; PCA: Principal Component Analysis; PNC: Postnatal Care; SBA: Skilled Birth Attendance; SDGs: Sustainable Development Goals; SII: Slope index of; SNNP: South Nations Nationalities Peoples Region; SSA: Sub-Saharan African

\section{Acknowledgments}

We thank Professor Aluísio J D Barros, Federal University of Pelota, for offering permission and aiding in using STATA commands for the concentration index, slope index of inequity, and equiplot.

\section{Authors' contributions}

$A D$ and $Y O$ participated in the idea conception and design of the study, data collection and quality control, data analysis and interpretation, write up and submission of a manuscript to the journal. AAM, AMB, LP, and JS participated in the idea conception and design of the study and write up and editing of the manuscript. All authors read and approved the final version of the manuscript.

\section{Authors' information}

\section{Not applicable.}

\section{Funding}

The source of funding was the Bill\& Melinda Gates Foundation (OPP1132551) through the London School of Hygiene and Tropical Medicine and the Ethiopian Public Health Institute.

\section{Availability of data and materials}

The complete dataset will be available from the data repository center of $\mathrm{EPHI}$ upon request.

\section{Ethics approval and consent to participate}

Ethical approval was obtained from the Ethiopian Public Health Institute (SERO-012-8-2016; Version 001), London School of Hygiene and Tropical Medicine (LSHTM Ethic Ref: 11235), and from the IRB office of College of Health Sciences of Mekelle University in Ethiopia (ERC 1434/2018). Written consent and assent were also obtained from the participants.

\section{Consent for publication}

Not applicable.

\section{Competing interests}

We, the authors, declare that we don't have any competing interests.

\section{Author details}

${ }^{1}$ School of Public Health, College of Health Sciences, Mekelle University, Mekelle, Ethiopia. ${ }^{2}$ London School of Hygiene \&Tropical Medicine, London, UK. ${ }^{3}$ Ethiopian Public Health Institute, Addis Ababa, Ethiopia.

\section{Received: 19 July 2019 Accepted: 11 December 2019}

\section{Published online: 23 December 2019}

\section{References}

1. Whitehead M. The concept and principles of equity in Health. Int J Heal. 1992;22:429-45

2. Health IJP, Çalışkan Z, Kılıç D, Öztürk S, Atılgan E. Equity in maternal health care service utilization: a systematic review for developing countries. Int J Public Health. 2015;60(7):815-25.

3. Alam N, Hajizadeh M, Dumont A, Fournier P. Inequalities in maternal health care utilization in sub-saharan African countries: A multiyear and multicountry analysis. PLoS One. 2015;10(4):1-16.

4. Memirie ST, Verguet S, Norheim OF, Levin C, Johansson KA. Inequalities in utilization of maternal and child health services in Ethiopia: the role of primary health care. BMC Health Serv Res. 2016;16(1):51.
5. Wagstaff A Van DA. EQUITY IN HEALTH CARE FINANCE AND DELIVERY United Kingdom: School of Social Sciences, University of Sussex; 1998

6. (WHO) WHO. CLOSING THE HEALTH EQUITY GAP : Policy options and opportunities for action. World Heal Organ [Internet]. 2013; Available from https://apps.who.int/iris/bitstream/handle/10665/78335/9789241505178_ eng.pdf? sequence $=1$.

7. Blas E, Kurup A. Equity, Social determinants, and public health programmes. World Health Organization; 2010.

8. Victora CG, Wagstaff A, Schellenberg JA, Gwatkin D, Claeson M, Habicht JP. Applying an equity lens to child health and mortality: more of the same is not enough. Lancet. 2003;362(9379):233-41.

9. Hosseinpoor AR, Bergen N, Schlotheuber A, Williams JS. Monitoring Health Determinants With an Equity Focus, Promoting health equity: WHO health inequality monitoring at global and national levels. Glob Health Action [Internet]. 2015;8:1-8. Available from: https://doi.org/10.3402/gha.v8.29034.

10. Ethiopia., FMOH. Federal Ministry of Health of Ethiopia. HSTP: Health Sector Transformation Plan 2015/16-2019/20. 2015.

11. Admasu K, Balcha T, Ghebreyesus TA. Pro-poor pathway towards universal health coverage: lessons from Ethiopia. J Glob Health. 2016;6(1):6-9.

12. Barros AJD, Ronsmans C, Axelson H, Loaiza E, Bertoldi AD, França GVA, et al. Equity in maternal, newborn, and child health interventions in countdown to 2015: a retrospective review of survey data from 54 countries. Lancet. 2012;379(9822):1225-33.

13. Central Statistical Agency. Ethiopia Demographic and Health Survey 2016: Key Indicators Report. Addis Ababa, Rockville: Central Statistical Agency [Ethiopia] ICF; 2016.

14. Houweling T, Ronsmans C, OMR C, KA. Huge poor-rich inequalities in maternity care: an international comparative study of maternity and childcare in developing countries. Bull World Health Organisation. 2007;85:745-54.

15. Karim AM, Tamire A, Medhanyie AA, Betemariam W. Changes inequity of maternal, newborn, and child health care practices in 115 districts of rural Ethiopia: implications for the health extension program. BMC Pregnancy Child Heal. 2015;15(238):1-11.

16. Bobo FT, Yesuf EA, Woldie M. Inequities in utilization of reproductive and maternal health services in Ethiopia. Int J Equity Health. 2017;16(1):1-8.

17. Barros AJD, Victora CG. Measuring Coverage in $\mathrm{MNCH}$ : Determining and Interpreting Inequalities in Coverage of Maternal, Newborn, and Child Health Interventions. PLoS Med [Internet]. 2013;10(5):1-9. Available from: https://journals.plos.org/plosmedicine/article?id=10.1371/journal.pmed.1 001390.

18. Gebre E, Worku A, Bukola F. Inequities in maternal health services utilization in Ethiopia 2000-2016: magnitude, trends, and determinants. Reprod Health. 2018;15(1):119.

19. ONU. (2017). World Population Prospects, the 2017 Revision: Methodology of the United Nations Population Estimates and Projections [Internet]. World population review. 2019. Available from: https://esa.un.org/unpd/wpp/ Publications/Files/WPP2017_Methodology.pdf.

20. Ryan BL, Krishnan RJ, Terry A, Thind A. Do four or more antenatal care visits increase skilled birth attendant use and institutional delivery in Bangladesh? A propensity-score matched analysis. BMC Public Health. 2019;19(1):1-6.

21. Restrepo-Méndez MC, Barros AJ, Wong KL, Johnson HL, Pariyo G, França GV, et al. Inequalities in full immunization coverage: trends in low- and middleincome countries. Bull World Health Organ. 2016;94(11):794-805B.

22. Vyas S, Kumaranayake L. Constructing socio-economic status indices: how to use principal components analysis. Health Policy Plan [internet]. 2006;21(6):459-68. Available from: http://www.ncbi.nlm.nih.gov/ pubmed/17030551.

23. Moreno-betancur M, Latouche A, Menvielle G, Kunst AE, Rey G. Relative index of inequality and slope index of inequality a structured regression framework for estimation. Epidemiology [internet], Available from. 2015;26(4):518-27 https://www.ncbi.nlm.nih.gov/pubmed/26000548.

24. International Center for Equity in Health. Equiplot [Internet]. Universidade Federal de Pelotas, Brazil. 2017 [cited 2019 Mar 21]. Available from: http:// www.equidade.org/equiplot.php

25. Neal S, Channon AA, Carter S, Falkingham J. Universal health care and equity : evidence of maternal health based on an analysis of demographic and household survey data. Int J Equity Health [Internet]. 2015;14:1-12. Available from: https://doi.org/10.1186/s12939-015-0184-9.

26. Ambel AA, Andrews C, Bakilana AM, Foster EM, Khan Q, Wang H. Examining changes in maternal and child health inequalities in Ethiopia. Int J Equity Health. 2017;16(1):1-16. 
27. Yaya S, Uthman OA, Amouzou A, Ekholuenetale M, Bishwajit G. Inequalities in maternal health care utilization in Benin: a population-based crosssectional study. BMC Pregn Childbirth. 2018;18:194.

28. Mwase T, Brenner S, Mazalale J, Lohmann J, Hamadou S, Somda SMA, et al. Inequities and their determinants in coverage of maternal health services in Burkina Faso. Int J Equity Health.

29. Nghargbu R, Olaniyan O. Inequity in maternal and child Health care utilization in Nigeria. African Dev Rev. 2017;29(4):630-47.

30. Paredes, Karlo Paolo P. Inequality in the use of maternal and child health services in the Philippines: do pro-poor health policies result in more equitable use of services? Int J Equity Health [Internet]. 2016;15(181):1-11. Available from: https://doi.org/10.1186/s12939-016-0473-y.

31. Akseer N, Bhatti Z, Rizvi A, Salehi AS, Mashal T, Bhutta ZA. Coverage and inequalities in maternal and child health interventions in Afghanistan. BMC Public Health. 2016:16(419):120-37.

32. Zere E, Suehiro Y, Arifeen A, Moonesinghe L, Chanda SK, Kirigia JM. Equity in reproductive and maternal health services in Bangladesh. Int J Equity Health [Internet]. 2013;12(90):1-8 Available from: http://www.equityhealthj. com/content/12/1/90

33. Malik SM, Ashraf N. Equity in the use of public services for mother and newborn child health care in Pakistan: a utilization incidence analysis. Int J Equity Health. 2016;15(1):1-12.

34. Myint ANM, Liabsuetrakul T, Htay T, Wai MM, Sundby JBE. Inequity in the utilization of antenatal and delivery care in Yangon region, Myanmar: a cross-sectional study. Int J Equity Health. 2018;17(63):1-9.

35. Countdown to 2030 Collaboration. Review Countdown to 2030: tracking progress towards universal coverage for reproductive, maternal, newborn, and child health. Lancet [Internet]. 2018;6736(18):1-11. Available from: www. thelancet.com

36. Raza O, Lodhi FS, Morasae EK, Majdzadeh R. Differential achievements in childhood immunization across geographical regions of Pakistan: analysis of wealth-related inequality. Int J Equity Health. 2018;1-8.

37. Kok MC, Kea AZ, Datiko DG, Broerse JEW, Dieleman M, Taegtmeyer M, et al. A qualitative assessment of health extension workers ' relationships with the community and health sector in Ethiopia : opportunities for enhancing maternal health performance. Hum Resour Health. 2015;13(80):1-12.

38. Jackson R, Hailemariam A. The role of Health extension Workers in Linking Pregnant Women with Health Facilities for delivery in rural and pastoralist areas of Ethiopia. Ethiop J Heal Sci. 2016;26(5):471-8.

39. Amare SA. The Impact of Ethiopian Health Services Extension Program on Maternal and Child Health Outcomes: The Case of Tigray Region. Thesis. Georg State Univ [Internet]. 2013. p. 1-43. Available from: https:// scholarworks.gsu.edu/iph_theses/257.

40. Desta SH, Basha SY. The role of Health extension Workers in Primary Health Care in AsgedeTsi ' mbla district : a case of Lim'at T'abya Health post. Int J Soc Sc Manag. 2017;4(4):248-66.

41. Ahmed S, Khan MM. Social Science \& Medicine is demand-side fi nancing equity enhancing ? Lessons from a maternal health voucher scheme in Bangladesh. Soc Sci Med [Internet]. 2011;72(10):1704-10 Available from: https://doi.org/10.1016/.jocscimed.2011.03.031.

42. Countdown to 2015. Countdown to 2015 Maternal, Newborn and Child Survival. Countdown Equity Analysis by Country. Supplementary file to the 2015 countdown report. Int J Equity Health. 2015;

\section{Publisher's Note}

Springer Nature remains neutral with regard to jurisdictional claims in published maps and institutional affiliations.

Ready to submit your research? Choose BMC and benefit from:
- fast, convenient online submission
- thorough peer review by experienced researchers in your field
- rapid publication on acceptance
- support for research data, including large and complex data types
- gold Open Access which fosters wider collaboration and increased citations
- maximum visibility for your research: over 100M website views per year
At BMC, research is always in progress.
Learn more biomedcentral.com/submissions

